\title{
$\mathrm{PH} 99_{\text {actualidad }}$
}

\section{Islas Baleares aprueba una nueva ley de salvaguarda del patrimonio inmaterial con el acento en la comunidad}

El pasado mes de abril el Parlamento de Islas Baleares aprobó la Ley de salvaguarda del patrimonio cultural inmaterial de las Illes Balears. En esta breve reseña, además de la asignación de competencias y las categorías de protección que establece la norma, a modo de conceptos antagónicos, se apuntan tres cuestiones especialmente relevantes: el carácter inmutable de la tradición frente al dinamismo y la continua adaptación, transformación y recreación del patrimonio; el control y el grado de participación de los distintos actores en los procesos de patrimonialización y, finalmente, la disyuntiva entre la precisa opción conservacionista y la salvaguarda en una modernidad líquida.

Andreu Ramis Puig-Gros | Consell Assessor de Cultura Popular de les Illes Balears

Url de la contribución <www.iaph.es/revistaph/index.php/revistaph/article/view/4536>

La tramitación y posterior aprobación de la Ley 18/2019, de 8 de abril, de salvaguarda del patrimonio cultural inmaterial de las Illes Balears (BOIB n. ${ }^{\circ} 43$, de 13 de abril) puede interpretarse como una respuesta a un contexto. La necesidad de contribuir a la salvaguarda de alg(una) identidad es, sin lugar a dudas, una de las claves políticas de esta iniciativa legislativa. Nos encontramos, pues, ante un pretexto que puede parecer quimérico, pero que puede explicarse a partir del preámbulo de la misma norma. El estrés provocado por la carga turística sobredimensionada, la huella ecológica, los fenómenos de gentrificación a la que se ven sometidos los principales centros históricos de las islas; una multiculturalidad un tanto exacerbada y, recientemente, una velada o no tan velada pretensión recentralizadora por parte del Estado, son algunos de los más evidentes indicadores de una nueva realidad saturada. Estos y otros recurrentes pretextos noticiables en los medios de comunicación y objeto de debate en diversas y múltiples redes sociales apuntan a la percepción del cambio como una de las claves de los procesos de patrimonialización. Una constante secular que se reactiva con vigor y nos sitúa de nuevo ante el dilema de concebir el patrimonio como síntoma o como oportunidad.

Lógicamente, una de las novedades que aporta la Ley es el nuevo enfoque conceptual emanado de la convención de París de 17 de octubre de 2003. En este sentido, se supera la anterior Ley 1/2002 de cultura popular y

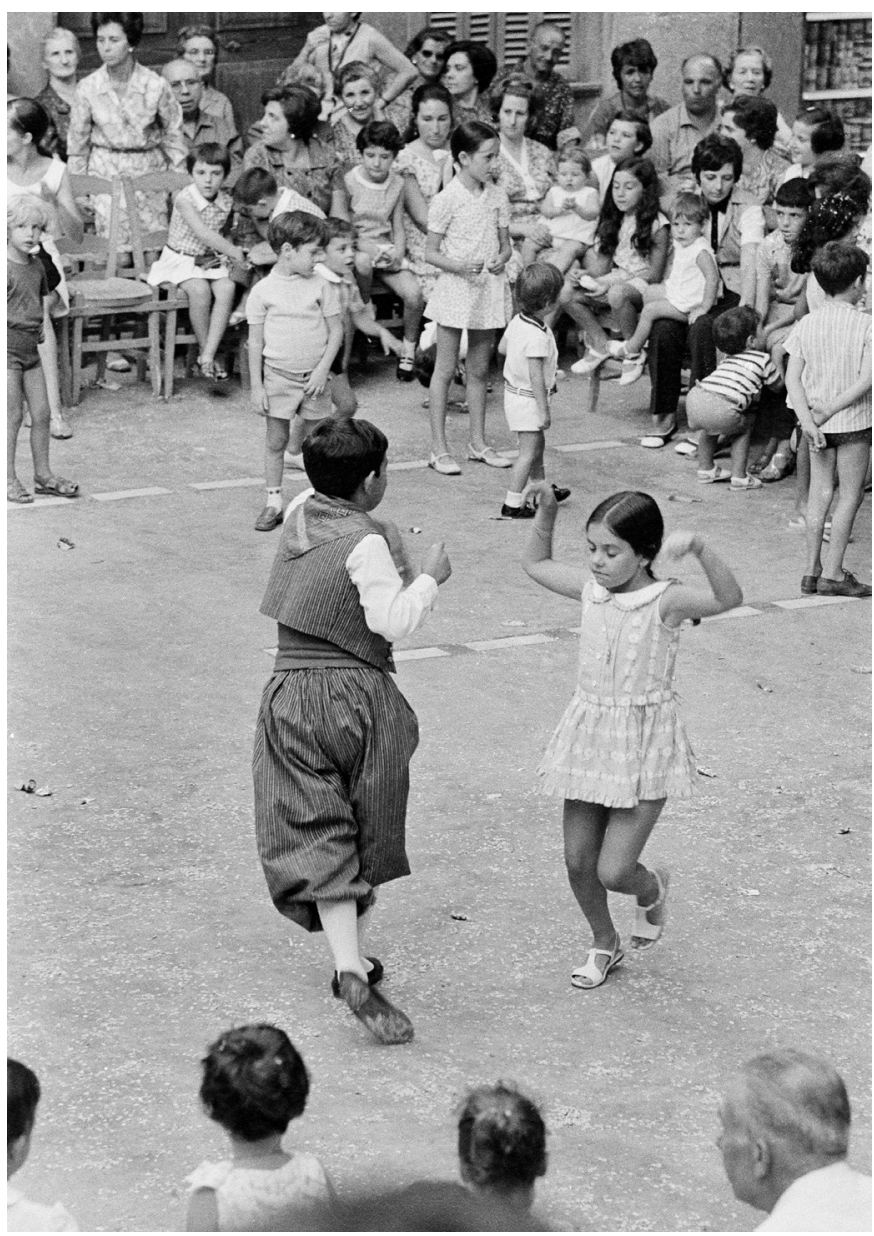

Fiesta. Cordelia Weedon, 1969. Fons Tom i Cordelia Weedon | foto ASIM (Consell de Mallorca S/T) 


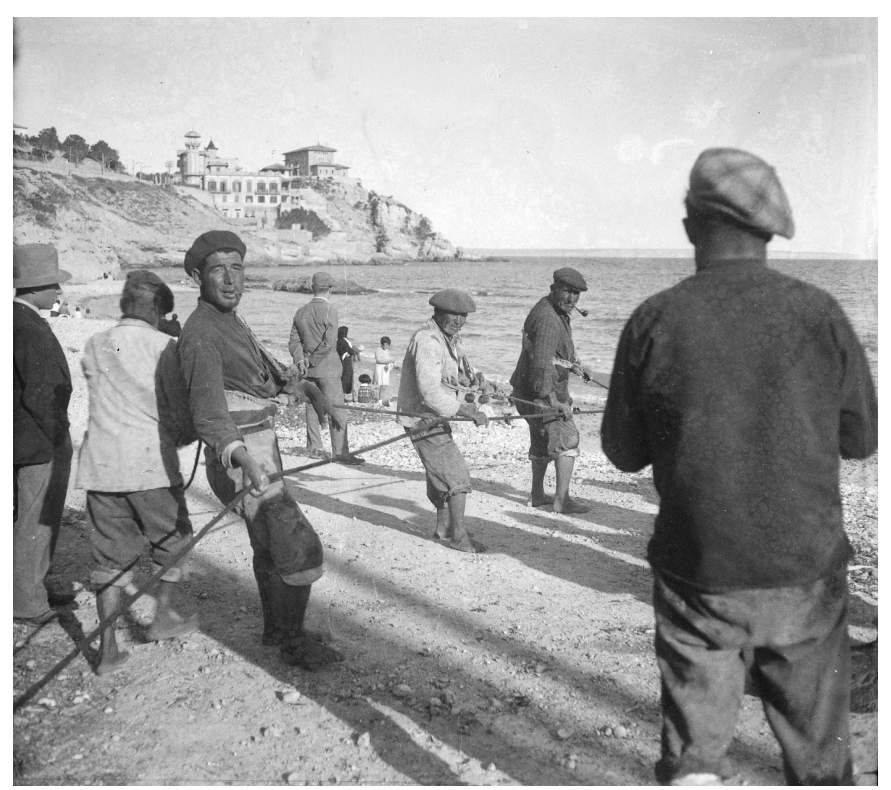

Gaspar Rul·lan, c.1925. Fons Rul·lan | foto ASIM (Consell de Mallorca)

tradicional de las Islas Baleares y se afrontan tres antagonismos que, a mi parecer, han estado instalados en la mente de buena parte de los actores y gestores del patrimonio inmaterial. A saber: el carácter inmutable de la tradición frente al dinamismo y la continua adaptación, transformación y recreación del patrimonio; el control y el grado de participación de los distintos actores en los procesos de patrimonialización y, finalmente, la disyuntiva entre la precisa opción conservacionista y la salvaguarda en una modernidad líquida.

Sin entrar en detalles en los matices conceptuales que la nueva Ley aborda en la amplia exposición de motivos y en el Capítulo I de disposiciones generales, cabe centrar la atención en el régimen y las medidas de salvaguarda y las previstas actuaciones de protección, promoción y fomento (cap. II, III y IV). En lo que atañe a los procesos de patrimonialización, la Ley, en sintonía con la normativa de rango superior y siguiendo la inercia administrativa, otorga la competencia sobre los inventarios del $\mathrm{PCl}$ a los Consells insulares (art. 9) y establece sus categorías -bienes catalogados inmateriales $(\mathrm{BCl})$, bienes de interés cultural inmaterial (BICIM) y bienes de interés cultural inmaterial compartido (BICIMCO) y procedimientos de incoación (art. 11-18). Es en este entorno procedimental donde la experiencia permitirá evaluar el grado y la calidad de la participación de los portadores y observar cómo la atención pasa del objeto - de la manifestación, del proceso o del bien- al sujeto portador -comunidad, grupo o persona- que lo protagoniza y lo reconoce como parte integrante de su patrimonio cultural en función de su aportación identitaria. En este aspecto resultará ilustrativo el pertinente seguimiento y revisión que los portadores deberán hacer de la decena de reconocimientos de fiesta de interés cultural (FIC) que se han llevado a cabo entre 2007 y 2018 y que, por la disposición adicional segunda de la nueva Ley, pasan a tener la consideración de BICIM.

De forma paralela al reto de los portadores, en las Baleares, la discontinuidad territorial que impone la insularidad aporta, por una parte, diversidad y riqueza, y, por otra, puede representar disparidad de criterios, ritmos distintos y dificultad en la tramitación de algunos elementos compartidos. Este podría ser el caso de la declaración de BICIMCO. Sin embargo, la reciente declaración consecutiva de BICIM -al amparo de la Ley 12/1998, de 21 de diciembre, del patrimonio histórico de les Illes Balears- como bien de interés cultural inmaterial de la técnica tradicional de construcción con piedra seca, por parte de cada uno de los Consells insulares, permite vislumbrar una perspectiva optimista. En esta misma línea, creemos muy positivo el convenio de los Consells de Menorca i de Mallorca con el Institut Ramon Muntaner (IRMU) para la ejecución de los respectivos inventarios de patrimonio cultural inmaterial. La experiencia del IRMU en inventarios de distintas comarcas de Cataluña y la posibilidad de utilizar la misma plataforma tecnológica, así como la misma metodología y expertise son, desde mi punto de vista, una garantía de éxito de cara a una visión global tan necesaria en territorios de lengua y cultura compartidas.

Por último, cabrá ver qué papel juega la nueva ley -en un entorno mutante como el que anunciábamos al inicio-, de cara a la adopción de medidas encaminadas a garantizar la viabilidad del $\mathrm{PCl}$, reforzando las diversas condiciones materiales o inmateriales imprescindibles para la transformación e interpretación continuas de este patrimonio, así como para su transmisión a las generaciones futuras. 